Conceptual model of a future farm management information system

Sørensen, C.G.; Fountas, S.; Nash, E.; Personen, L.; Bochtis, D.; Pedersen, Søren Marcus; Basso, B.; Blackmore, S.B.

Published in:

Computers and Electronics in Agriculture

DOI:

10.1016/j.compag.2010.02.003

Publication date:

2010

Document version

Publisher's PDF, also known as Version of record

Citation for published version (APA):

Sørensen, C. G., Fountas, S., Nash, E., Personen, L., Bochtis, D., Pedersen, S. M., Basso, B., \& Blackmore, S. B. (2010). Conceptual model of a future farm management information system. Computers and Electronics in Agriculture, 72(1), 37-47. https://doi.org/10.1016/j.compag.2010.02.003 


\title{
Conceptual model of a future farm management information system
}

\author{
C.G. Sørensen ${ }^{\mathrm{a}, *}$, S. Fountas ${ }^{\mathrm{b}}$, E. Nash $^{\mathrm{f}}{ }^{\text {, L. Pesonen }}{ }^{\mathrm{d}}$, D. Bochtis ${ }^{\mathrm{a}}$, S.M. Pedersen ${ }^{\mathrm{e}}$, \\ B. Basso ${ }^{\text {C }, ~ S . B . ~ B l a c k m o r e ~}{ }^{g}$ \\ a Århus University, Faculty of Agricultural Sciences, Department of Agricultural Engineering, Research Centre Foulum, Blichers Alle 20, 8830 Tjele, Denmark \\ b Center for Research and Technology, Institute of Technology and Management of Agricultural Ecosystems, Technology Park of Thessaly, 1st Industrial Area, \\ GR 385 00, Volos, Greece \\ ' University of Basilicata (UNIBAS), Via N. Sauro, 85-(85100) Potenza, Italy \\ ${ }^{\mathrm{d}}$ MTT Agrifood Research Finland, Vakolantie 55, 03400 Vihti, Finland \\ e Institute of Food and Resource Economics, University of Copenhagen, Rolighedsvej 25, 1958 Frederiksberg C, Denmark \\ ${ }^{\mathrm{f}}$ Rostock University, Faculty of Agricultural and Environmental Sciences, Institute for Management of Rural Areas, Justus-von-Liebig-Weg 6, 18059 Rostock, Germany \\ g King Saud University, Riyadh 11451, Saudi Arabia
}

\section{A R T I C L E I N F O}

\section{Article history:}

Received 23 July 2009

Received in revised form

26 December 2009

Accepted 17 February 2010

\section{Keywords:}

System boundary

Future farm

ICT

Information systems

\begin{abstract}
A B S T R A C T
Future and even current European farmers are experiencing that the managerial tasks for arable farming are shifting to a new paradigm, requiring increased attention to economic viability and the interaction with the surroundings. To this end, an integration of information systems is needed to advise managers of formal instructions, recommended guidelines and documentation requirements for various decision making processes. In the EU funded project FutureFarm, a new model and prototype of a new Farm Information Management System (FMIS) which meets these changing requirements will be developed. The aim of the work presented in this paper is to define and analyse the system boundaries and relevant decision processes for such a novel FMIS as a prerequisite for a dedicated information modelling.

The boundaries and scope of the system are described in terms of actors and functionalities, where actors are entities interfacing with the system (e.g. managers, software, databases). In order to analyse the complex and soft systems situations of how to develop an effective FMIS, which effectively meets farmers' changing needs a conceptual model was developed based on soft systems methodology (SSM) and based on information derived from four pilot farms representing diverse conditions across the EU that are partners of the FutureFarm project. The system components were depicted as part of rich pictures and linked to the subsequent derived conceptual model of the overall system as an outline for the development of the specific FMIS requirements. This research has shown the benefit of using dedicated system analysis methodologies as a preliminary step to the actual design of a novel farm management information system compared with other more rigid and activity oriented system analysis methods.
\end{abstract}

(c) 2010 Elsevier B.V. All rights reserved.

\section{Introduction}

The managerial tasks in agriculture are currently shifting to a new paradigm, requiring more attention on the interaction with the surroundings, namely environmental impact, terms of delivery, and documentation of quality and growing conditions (e.g. Sigrimis et al., 1999; Dalgaard et al., 2006). Among other things, this managerial change is caused by external entities (government, public) applying increasing pressure on the agricultural sector to change production from a focus on quantity to an alternate focus on quality and sustainability (Halberg, 2001). This change has been enforced by provisions and restrictions in the use of production

\footnotetext{
* Corresponding author. Tel.: +45 89991930.

E-mail address: claus.soerensen@agrsci.dk (C.G. Sørensen).
}

input (e.g. fertilisers, agrochemicals) and with a change of emphasis for subsidies to an incentive for the farmer to engage in a sustainable production rather than based solely on production. In general, this change of conditions for the managerial tasks on the farm has necessitated the introduction of more advanced activities monitoring systems and information systems to secure compliance with the restrictions and standards in terms of specific production guidelines, provisions for environmental compliance and management standards as prerequisites for subsidies. Until now, farmers most often have dealt with this increased managerial load by trying to handle manual a mass of information in order to make correct decisions. The increasing use of computers and the dramatic increase in the use of the internet have to some degree improved and eased the task of handling and processing of internal information as well as acquiring external information. However, the acquisition and analysis of information still proves a demanding task, since information 
is produced from many sources and may be located over many sites and is not necessarily interrelated and collaborated. The potential of using these data will reach its full extent when suitable information systems are developed to achieve beneficial management practices (Blackmore et al., 2006). McCown (2002) argued that in designing an information system, the emphasis should be placed less on design and more on learning what the farmers do and how they act, and not only letting researchers design their own views of farm management decisions. Additionally, Alvarez and Nuthall (2006) while realizing that the technology in the farm office was not as extensive as they could expect, and while looking at the potential problems pointed out that software developers should understand the farmers and work closer with them and that the resulting systems should be adaptable to suit a range of farmer characteristics. Specific attempts to improve this situation have included the launch of "web-based collaborative information systems", combining different information components (models, data, text, graphics) from different but collaborating sources (e.g. Jensen et al., 2001). However, such systems still have to be enhanced in terms of collaboration with automated acquisition of operational farm data and integration with the overall Farm Management Information System (FMIS).

Advances in precision agriculture, such as positioning systems and sensors for yield and machinery performance monitoring allows farmers to acquire vast amount of site-specific data which ultimately can be used to enhance decision making (Blackmore, 2000; Fountas et al., 2006). Currently, however, this automatically collected data or data by manual registration is not used due to data logistic problems, leaving a gap between the acquiring of such data and the efficient use of this in agricultural management decisions making (Atherton et al., 1999; Pedersen et al., 2004; Reichardt and Juergens, 2009). Costs of time spent managing the data in many cases outweigh the economical benefits of using the data and it seems that future use of wireless communication is gaining much of interest (Speckman and Munach, 2001; Jensen et al., 2007). In all, a refined and integrated solution to analyse and transform the acquired data is needed to improve decision making in the future (Fountas et al., 2005).

With the current transformation of the agricultural sector and the need for better analysis and transformation of the collected data additional demands on the precision and integration of the planning and control functions have occurred, requiring that the planning considers the dynamic interaction of machine, biological, and meteorological conditions (e.g. Kuhlman and Brodersen, 2001). This resembles the industrial adoption of computer-integrated manufacturing (CIM) and it's embracing of customised production followed by dynamic operations planning and control of operations (Nagalingam and Grier, 2008). The industry has demonstrated how effective an integrated control of work operations can be, based on on-line measurements combined with database and decision support information (McCarthy, 1990; Riezebos et al., 2009). This is especially the case in terms of integrating information technology and information systems in supply chain activities (e.g. Gunasekaran and Ngai, 2004).

In this regard, it has been shown that the enhancement of FMIS is more influenced by common business factors and drivers than specific farming activities (Lewis, 1998). Plan generation and execution of farm operations must be linked with a system monitoring effects of actions, unexpected events and any new information that can contribute to a validation, refinement, or reconsideration of the plan or goal. Plans must be presented in a conditional way, such that supplementary knowledge from observations, databases, sensors and tests can be incorporated and integrated to revise the plan in the light of new information. This involves an extended use of modelling and simulation as opposed to providing a generalised optimal solution (Attonaty et al., 1999; Ohlmer et al., 1998).
A detailed structuring and formalisation of physical entities and the information which surrounds the planning and control of farm operations using efficient mobile working units in automated agricultural plant production systems is a decisive prerequisite for the development of comprehensive and effective ICT-system supporting the task management efforts. An increase in the adoption of new information technologies requires that the functional requirements surrounding the use of such technologies must be explicitly specified (Sørensen et al., 2007). By specifying in detail the information provided and the information required for the information handling processes, the design and functionalities of the individual information system components can be derived. That is the case both for on-board machinery information systems as well as for supporting service information systems. The information flows may be contextualised on different levels and in different details (e.g. Fountas et al., 2006; Sørensen et al., 2007; Nash et al., 2009a).

\subsection{Concept of management information systems (MIS)}

Management information systems (MIS) are an integral part of the overall management system in an purposeful organisation and form parts of tools such as enterprise resource planning (ERP) and overall information systems (IS). ERP is an industry notion for a wide set of management activities which support all essential business processes within the enterprise. The management systems support management activities on all levels as well as provide for the identification of key performance indicators (KPI's) (Folinas, 2007). Typically, ERP is directly integrated with information systems in the form of databases and will often include applications for the finance and human resources aspects of a business.

MIS differs from regular information systems because the primary objectives of these systems are to analyse other systems dealing with the operational activities in the organisation. In this way, MIS is a subset of the overall planning and control activities covering the application of humans, technologies, and procedures of the organisation. Within the field of scientific management, MIS is most often tailored to the automation or support of human decision making (O'Brien, 1999). Fig. 1 shows the conceptual decomposition of the different management systems in an organisation.

By following this conceptual framework and notation, a FMIS is defined as a planned system for the collecting, processing, storing and disseminating of data in the form of information needed to carry out the operations functions of the farm.

\subsection{Diversity of European agriculture}

The diversity among European agricultural holdings in terms of farm type, size, geography, cultural differences, etc. has a significant impact on the decision making process of the farmers (e.g. Ohlmer et al., 1998). By structuring the complexity of farms, regions, and technologies for information driven crop production, some indications have been derived which illustrate the issue of FMIS transferability within the EU. Likely issues for worldwide transferability may be extrapolated from this analysis.

The total agricultural area within EU-27 is about 183 million hectares - see Table 1 . About $85 \%$ of the farm holdings have an area below 20 ha (Danish Agriculture, 2007). The farm area structure varies from an average at about 5 ha per farm holding in Greece to 79 ha on average in the Czech Republic. With the accession of Romania and Bulgaria into the European Union, the number of farm holdings has increased significantly due to numerous small farms in Romania. About $32 \%$ of the agricultural area is cultivated with cereals of which wheat is the most common crop. About $40 \%$ of the cereals are produced in France and Germany. Farming has been less 
FARM SYSTEM

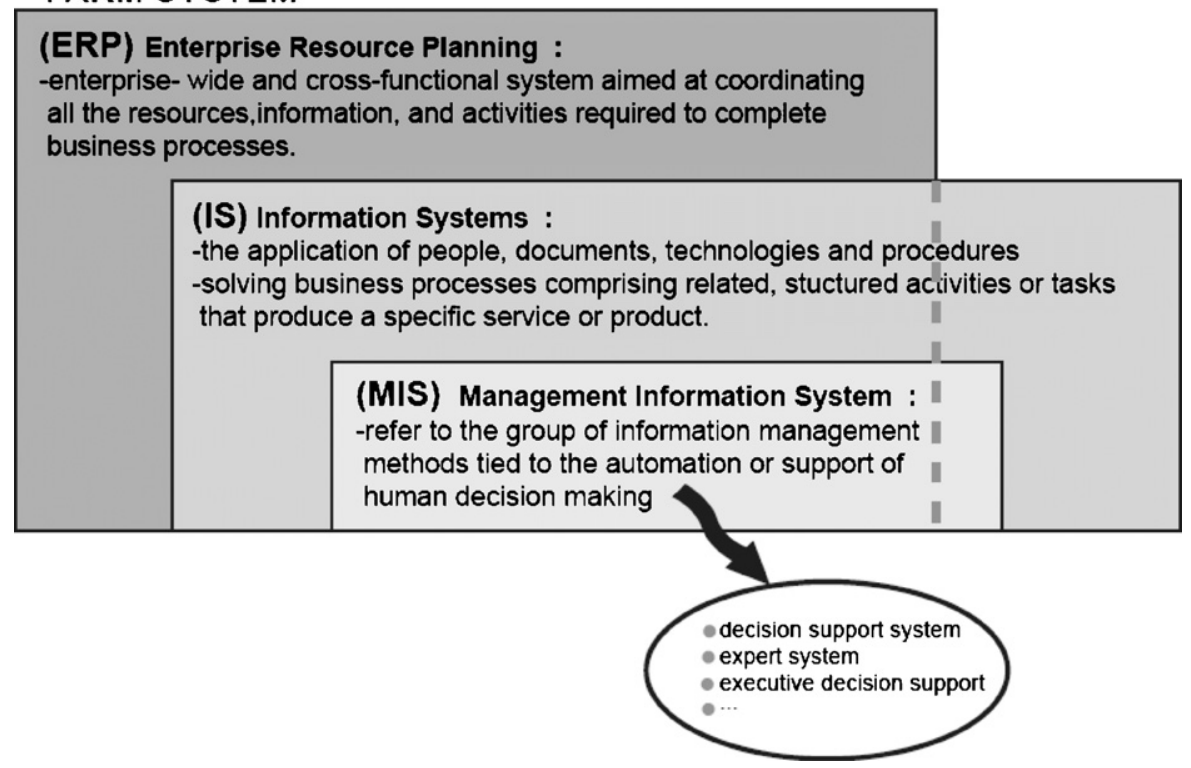

Fig. 1. Concept of management information systems (Sørensen et al., 2009).

intensive in many east European countries with reduced yields as a consequence - this may be seen in the two neighbouring countries Germany and Poland, where the difference in potato yield is significant.

Countries such as Denmark, besides crop production, focused on intensive animal production with a focus on pigs and dairy and related agricultural industries. The geographical and climatic differences determine that the cropping season, radiation and precipitation varies from the north to south. Crops such as olives, cotton and citrus, which are common in the Mediterranean countries, cannot be cultivated in the north, while for certain areas and crops it is possible to have several growing seasons during the same year.

Based on the outlined differences, it is inherent that new FMISs must be designed to accommodate the geographic and cultural differences among the European regions.

\subsection{Objectives}

The overall objective of this study was to create a basic outline and structure for a FMIS for planning and control of crop production by using the soft system methodology (SSM). This approach will guide the evolutionary process of analysing the information flows, defining the databases, knowledge encoding and requirements for on-line control. Specifically, it is the objective to understand the soft-system activities of farmers and produce a model of the individual FMIS components, indicating where the FMIS will be required to assist/enable information flows. Subsequently this model should be transformed into a format that computer scientists can use as the basis for a more formal and implementation-based description of the proposed FMIS (using e.g. $\mathrm{UML}$ ). Also, a further objective is to demonstrate how the applied SSM method can assist in the case of agriculture which has the special feature that the main actor (the farmer) is not an IT/computing specialist, giving the additional requirement that the resulting system model should be easily understood by the farmer, who may struggle to understand a formal systems model.

\section{Materials and methods}

The boundaries and scope of a system can be described in terms of users, where users are entities interfacing with the system (e.g. managers, software, databases). In order to analyse the complex and soft systems situations of how to develop an effective FMIS, the soft systems methodology (SSM) was used (Checkland and Scholes, 1999; Wilson, 2001). This approach involves identification of the scope of the system, identification of user requirements and conceptual modelling. It has been successfully used in many fields of

Table 1

Farm production and structure among selected countries 2007 (Danish Agriculture, 2007).

\begin{tabular}{|c|c|c|c|c|c|c|c|}
\hline & Population (M) ${ }^{\mathrm{a}}$ & Area (Mha) & Agriculture (Mha) & Farm holdings $(\mathrm{K})^{\mathrm{b}}$ & Area per farm holding (ha) & Cereals (Mha) & Cereals (Mt) \\
\hline Czech Republic & 10.2 & 7.9 & 3.6 & 46 & 79 & 1.6 & 7.7 \\
\hline Denmark & 5.4 & 4.3 & 2.7 & 49 & 55 & 1.5 & 9.3 \\
\hline Germany & 82.5 & 35.7 & 17 & 412 & 41 & 6.8 & 46 \\
\hline Greece & 11.1 & 13.2 & 3.8 & 824 & 5 & 1.2 & 4.2 \\
\hline Spain & 43.0 & 50.5 & 25.7 & 1141 & 23 & 6.5 & 13.3 \\
\hline France & 60.6 & 54.9 & 29.6 & 614 & 48 & 9.1 & 64.1 \\
\hline Italy & 58.5 & 30.1 & 14.7 & 1964 & 7 & 3.8 & 20.1 \\
\hline Slovakia & 5.4 & 4.9 & 1.9 & 72 & 26 & 0.8 & 3.6 \\
\hline Austria & 8.2 & 8.4 & 3.3 & 174 & 19 & 0.8 & 4.9 \\
\hline Finland & 5.2 & 33.8 & 2.3 & 75 & 31 & 1.2 & 4.1 \\
\hline UK & 60 & 24.4 & 16.8 & 281 & 60 & 2.9 & 21.0 \\
\hline EU-27 & 488.8 & 432.1 & 183.3 & 15.022 & 12 & 59.2 & 284.9 \\
\hline
\end{tabular}

a Million.

b Thousands. 


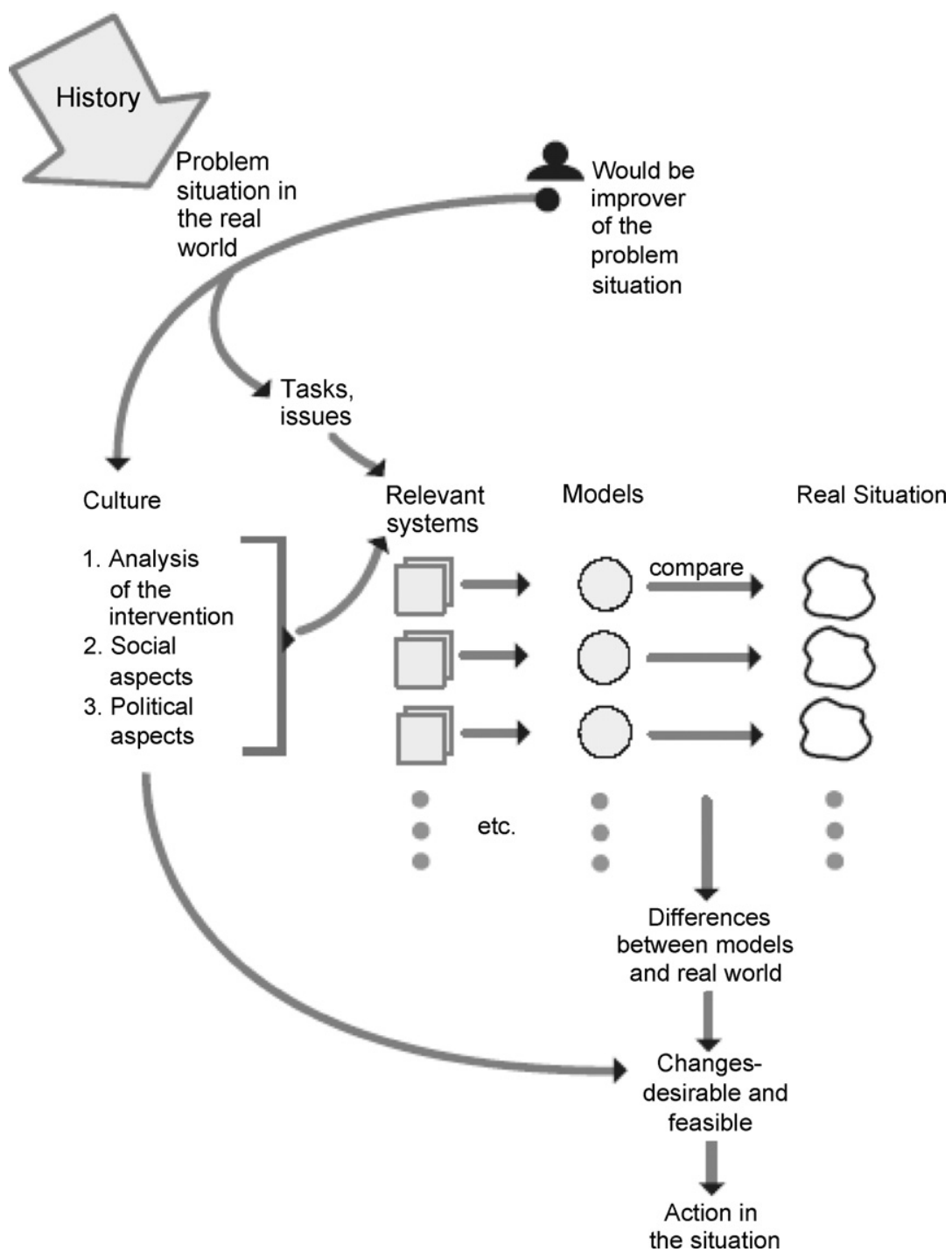

Fig. 2. An outline of the process of soft system methodology (Checkland, 1988).

applications from the health service (e.g. Checkland and Scholes, 1999) to urban development (e.g. Kasimin and Yusoff, 1996) as well as military operations (Staker, 1999). The application of SSM in agriculture is covering a large number of agricultural domains such as the grain, sugar or beef industry (e.g. Macadam et al., 1990; Reid et al., 2000; Walker et al., 2001; Carberry et al., 2002; McCown 2002; Fountas et al., 2009).

\subsection{Soft system methodology}

Fig. 2 illustrates the process of SSM, basically comprising of the modelling of human activity systems, which can then be compared with the real-world and an idealised future situation in order to facilitate and structure further discussions and elaborations and changes. The outcome from this process is a model widely agreed by all actors (in this case, those involved in the farming system) and facilitators (in this case, the authors of this paper) to be relevant to the particular situation. SSM are divided into three main parts: exploring the current situation, building models and taking action (Checkland, 1988). As illustrated in Fig. 2, the approach is based on a comparison between real-world problem situations and conceptual models of proposed relevant system for dealing with these problems (Nidumolu et al., 2006). SSM consist of the analysis of the current status quo of the system including inherent problems and activities, the definition of the system deriving the actual goal of the targeted system ("root definition") and, finally, the proposed conceptual model for the development of the information system.

\subsection{Empirical data and information}

The system analysis and boundary specification was based on extracted data and information obtained from the pilot farms involved in the FutureFarm project. These farms were the WIMEX farm located in Germany, MESPOL MEDLOV farm in Czech Republic, Markinos farm in Greece and Bramstrup farm in Denmark.

The selected farms represent a wide range of regional characteristics in Europe as well as farm types. These ranges are necessary to allow sufficient coverage of relevant patterns of information demand and flow as well as their technical handling on the widely different European farms. The four pilot farms represent: (i) large conventional cash-crop farming systems as being typical for main-stream farming, having specific problems in managing huge information clusters, internally as well as externally (WIMEX farm), (ii) cash-crop farming systems under transformation conditions and growing in size with their specificity in a still very dynamic information and internal management environment and internal management (MESPOL MEDLOV), (iii) organic farming systems with special information management related to long- 
term planning, ecology and consumer-relations (Bramstrup farm), and (iv) family farming systems with cash-crop production plus specialisation in a perennial crop and thus mixed information characteristics (Marinos farm).

\subsection{Analysis phase}

The analysis phase involved the identification of the system components applied to farm management and operations and the consideration of processes, conflicts and thoughts of an organisation as the basic outset for the design of a dedicated FMIS. The topics addressed with the four farmers were:

- What are the external actors the farm is dealing with (e.g. public entities, commercial companies, etc.)?

- What is working well in the farm (regarding particularly information management and exchange processes) and what is not working well and what would the farmer like to do about it?

- Regarding information processing, what would the farmer like to have to make their daily working life easier and to run the farm more effectively?

In order to achieve a better understanding of the current situation of the farm manager, the managers of the four pilot farms were asked to give their opinion about their specific situation which then formed the basis for developing a "rich picture" to describe soft and hard facts and the conflicts and problems that a farm manager currently faces, both from an external and as well as an internal point of view. The term 'rich picture' as used in SSM originates from recommendations made by Checkland and Scholes (1999), where this concept sums up the results of what the analyst undertakes and it is one of the first stages in the analysis of a problem situation. In this sense, a rich picture is an appreciation of the problem in the daily life of the farm managers today rather than a diagram as such, and the real utility of the picture is not in the picture itself, but in the process of constructing the picture. In this respect, the rich pictures were discussed with the four farm managers to ensure that their personal views were represented in the final version. By adhering to this approach, the analysis of the current situation includes the following steps:

- Record relationships, connections, influences, causes and effects among the entities in the domain being studied.

- Include also more subjective elements such as character and characteristics as well as points of view, prejudices, spirit and human nature.

- Draw up a rich picture as pictorial 'summaries' of the physical, conceptual and emotional aspects of the situation at a given time.

In order to be able to model the proposed FMIS, the requirements and surroundings of the system needs to be clearly outlined and defined. This definition is called the "root definition" and this concept plays a central role in the analysis and modelling as it defines the goal of the system and brings forth various perspectives on a system and the inherent assumptions (Bergvall-Kareborn et al., 2004). The root definition is devised in the form $P Q R$. A system to do $\mathrm{P}$, by means of $\mathrm{Q}$ to achieve $\mathrm{R}$ or "What to do (P), How to do it (Q), and Why do it (R)" (Checkland and Scholes, 1999). Special attention should be paid to the elements of CATWOE, a mnemonic word representing the terms Customers (C), Actors (A), Transformation process (T), World-view (W), Ownership (O) and Environmental constraints (E). The core of CATWOE is the T and the $\mathrm{W}$, where the World-view depicts the world-view for which the system has meaning and the Transformation depicts functionality on the system level. Customers are the ones influenced by the transformation as they benefit and suffer from it; Actors are the ones that carry out the system activity and the Ownership belongs to the ones with the power to initiate or terminate the activity system; and Environmental constraints represent elements which are taken as outside the system and imposed on the system. Checkland and Scholes (1999) argued that the CATWOE transformation is more to elaborate since it includes additional and related elements and when included, will lead to transformation in a more elaborate manner since it includes additional and related elements and will lead to enriched root definitions and hence, better models. Experience has shown that omitting any of the elements in the CATWOE definition will cause the analysis to suffer (Checkland and Scholes, 1999).

As every model should be evaluated for its performance, in the case of SSM this is attained by employing the 3Es: efficacy, efficiency and effectiveness, which encompass check of availability of system output, check on minimised resource input as well as a check on whether the system output supports the customer.

A conceptual model (Checkland, 1988) was formed to identify the main purposeful activities of the proposed FMIS through a set of logical actions implied by the root definition. The derivation of a conceptual model indicates the concept of the FMIS to be designed.

\section{Results}

The results from the study include the voiced concerns by the four farmers as the basis for developing the rich picture. Further, the rich picture forms the framework for defining the system in terms of derived situational elements of CATWOE.

\subsection{The current situation}

The important concerns and problems voiced by the farm manager include the time consuming tasks of monitoring field operations, manage the finances and application for subsidies which is further complicated by the lack of integrated soft and hardware to manage this work and the lack of coordination when such programs do exists. Also, the farmer voice a need for additional information and advanced technologies to manage monitoring and data acquisition on-line in the field. When looking at the external concerns, it mostly concerns the need for sustainable production of farm products, which is further pursued by regulations and the possibility to receive subsidies when more sustainable management practises are abided by. Table 2 lists the major concerns that the four farm managers expressed in terms of enhanced information handling at the farm level.

By using the voiced concerns of the farmers to frame the problem under study, the rich picture shown in Fig. 3 illustrates the current situation with its problems and conflicts. As it can be seen, the system structure is very complex and many external as well as internal entities and partners have an interest in the farming system.

In terms of information handling, the farmer needs to manage large amount of information in order to make economical and environmentally-sound decisions. Currently, this process is very labour intensive and for most parts is executed manually. The important concerns and problems communicated by the farm managers include the time required to monitor field operations; difficulties in managing the finances and applications for subsidies, which is further complicated by the lack of integrated software and hardware; and the lack of coordination when such programs do exist. The farm managers also expressed their need for additional information and advanced technologies to manage and monitor on-line data acquisition in the field. When looking at the external concerns, it is seen that this mostly refers to the need for sustainable production of farm products, which is further pursued by regulations and the possibility to receive subsidies when more sustainable management practises are abided by. 
Table 2

The concern of farm managers at the pilot farms.

\begin{tabular}{|c|c|c|}
\hline System components & Description & Problem, considerations \\
\hline People & $\begin{array}{l}\text { Central decision maker at the farm administration, district office, } \\
\text { farmers' association, local affairs, customers (e.g. direct marketing), } \\
\text { press and media, producers of agricultural equipment (direct or } \\
\text { through distributer), supplier of operating materials (like diesel, } \\
\text { fertiliser, pesticides, etc.), EU, the environment and relation with } \\
\text { neighbours, etc. }\end{array}$ & $\begin{array}{l}\text { - Often engulfed in routine tasks } \\
\text { - No time to concentrate on strategic issues } \\
\text { - Very complicated regulatory framework } \\
\text { - Good communication with commercial partner } \\
\text { - Positive experience with direct marketing } \\
\text { - Communication with external entities not optimal } \\
\text { - Low environmental impact } \\
\text { - Limited pollution } \\
\text { - Limited odour }\end{array}$ \\
\hline Activities/processes & $\begin{array}{l}\text { Tasks or tools capable of collecting data/information on activities and } \\
\text { processes at the farm: the acquisition of auxiliary materials and the } \\
\text { marketing of farm products, planning and control of farm employees, } \\
\text { extension services, etc. }\end{array}$ & $\begin{array}{l}\text { Data/information overload } \\
\text { No cross-linking of information } \\
\text { Needs information in an automated and } \\
\text { Summarised fashion } \\
\text { Lack of information on market } \\
\text { Acquisition of auxiliary' } \\
\text { Material confusing } \\
\text { Lack of easy accessible information on employee performance, etc. } \\
\text { Lack of user-friendly software tools }\end{array}$ \\
\hline
\end{tabular}

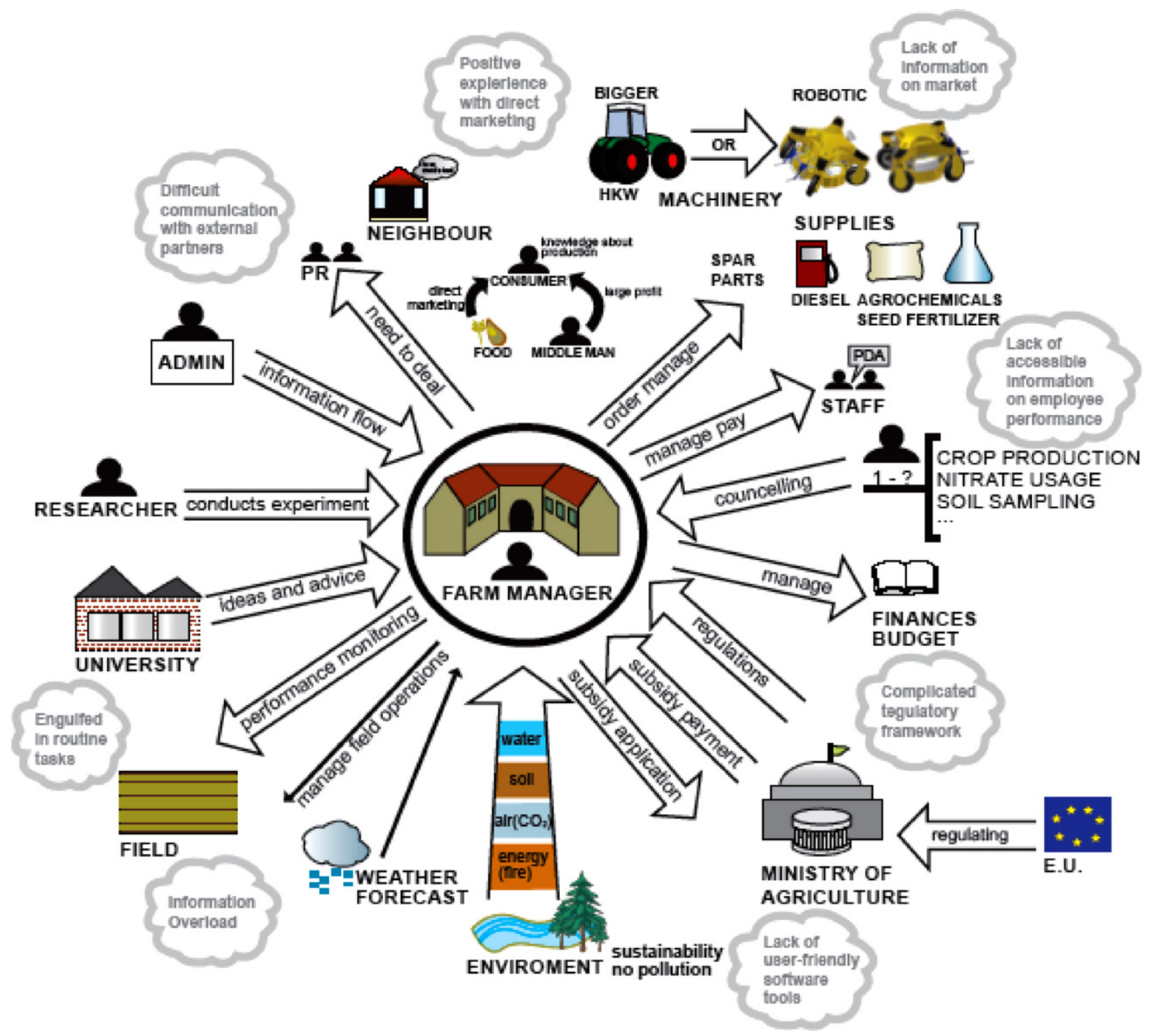

Fig. 3. The current situation with internal and external conflicts and problems. The drawing is based on general elaborations and answers to questions posed to farm mangers and the point of view of external partners involved in the study. The dark clouds symbolise conflict or problems, whereas the thick bobbles represent wants or needs for the future system. 


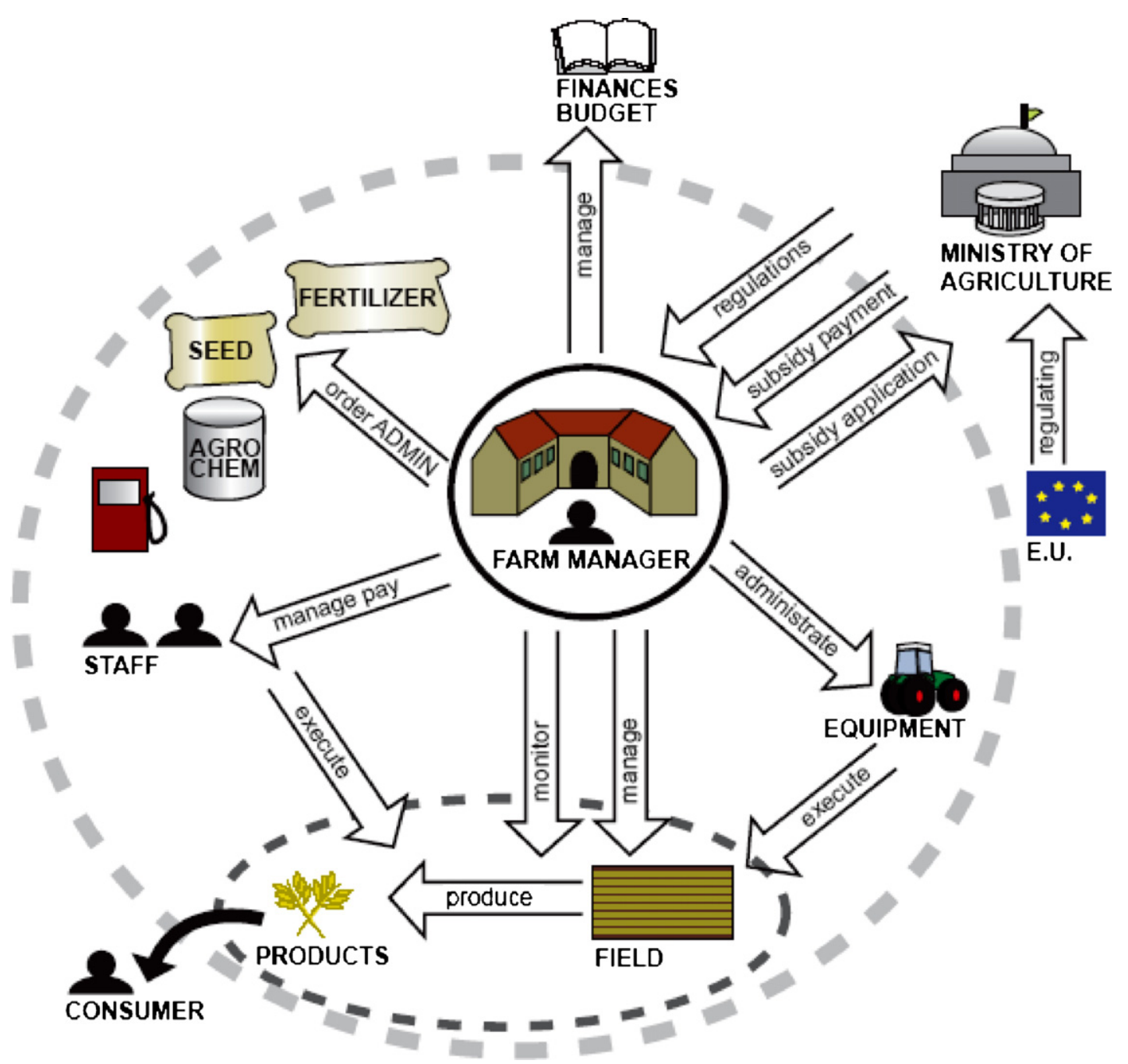

Fig. 4. The current situation seen from the farm manger's point of view and the farm activity system for production of crops (the dotted circle). The stippled line defines the farm system boundaries.

\subsection{Definition of the system}

To define the outline of the system a derived rich picture from Fig. 3 focussing on the farm manager and the subsequent everyday management problems were derived making the system easier to comprehend - see Fig. 4 . This figure shows the perceived boundaries of the proposed system.

The central entities in the proposed system include the farm manager, the fields, the products and production input. The Ministry of Agriculture and the consumer as external components are included since the system is very much influenced by these entities. Based on the boundaries identified above, the system was defined and the derived situational elements of CATWOE are listed below.

\subsubsection{CATWOE}

Customers. The primary customer of the proposed information system is the farm manager. The secondary customers are national and/or regional administrations, certification bodies, retailers, etc., understood as entities setting up and imposing standards and other regulatory frameworks for the farm production, and benefitting from the improved crop production.

Actors. The actor is the one operating the information system, which in this case is the farm manager or other farm staff.

Transformation process. The transformation process involves the transformation of operational field data into manageable infor- mation for regulatory purposes and decision making for crop production.

World-view. The World-view is the hypothesis that drives the information system development. In this case, the view is that operational data is easily acquired and can be used to improve management decision making throughout the production cycle, and that the same data may be used to demonstrate to external agencies the farm's compliance with standards.

Ownership. The farm manager is the owner in the way that he has everyday decision making responsibility, and decides whether the system is of use or not.

Environmental constraints. The constraints influencing the usability and performance of the information system includes the expectations of the regulators for readily-available information to audit compliance with the standards and regulations on the farm, as well as the reliability and structure of the information technology (communication devices, server, databases, etc.). Additionally, the form in which the requirements and expectations of the regulators are made available must be considered a constraint.

\subsubsection{Root definition}

The root definition of the purposeful activity handled, derived from the interviews with farmers, is: "a FMIS (operated on farm level) to support real-time management decision making and 


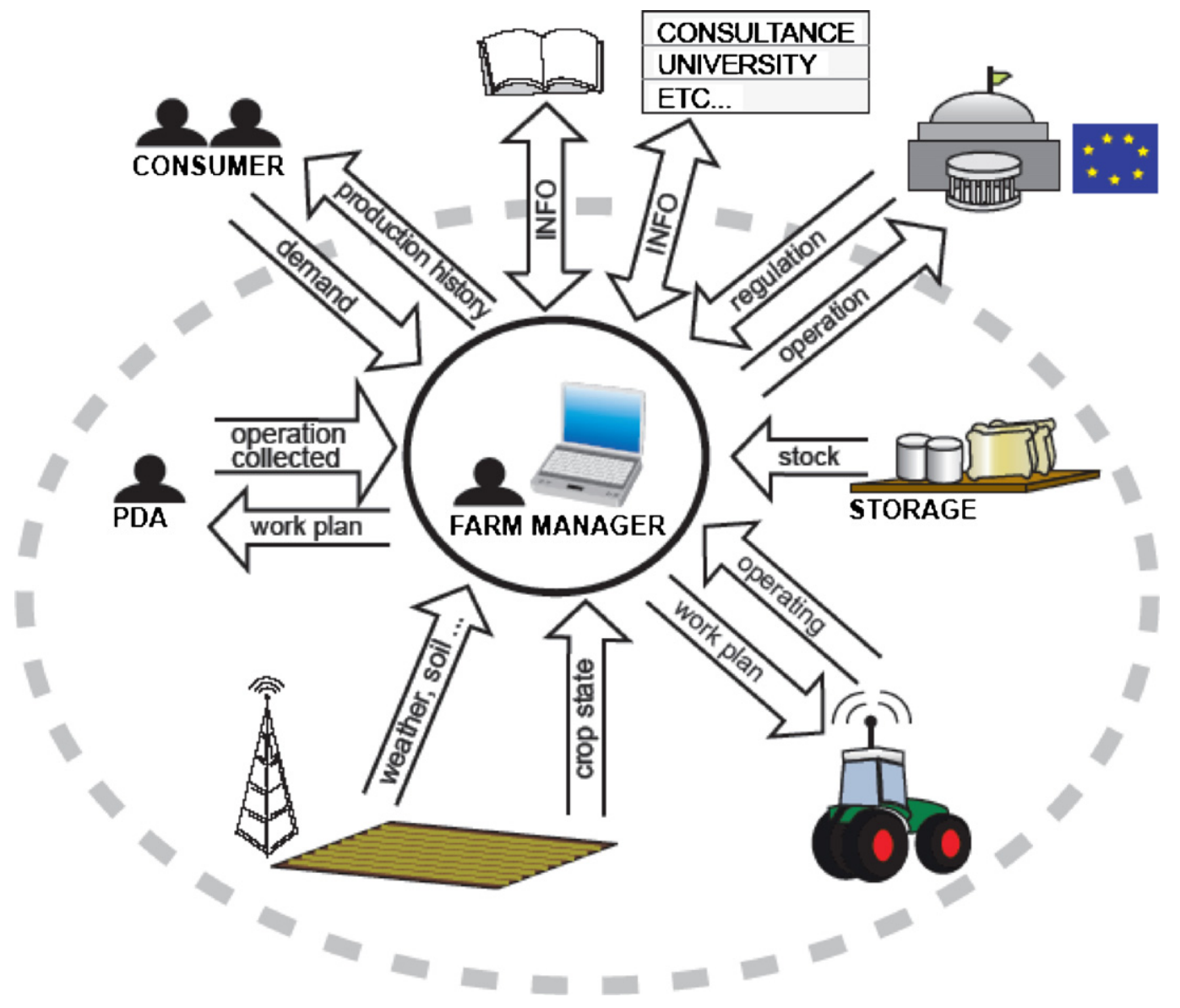

Fig. 5. The conceptual model.

compliance to management standards, by means of automated acquiring and contextualising operation data and external parameters (e.g. regulations, best management practises (BMP's), market information, etc.) to form a foundation for decision making in order to improve the quality of decision making and reduce the time required".

\subsubsection{The $3 E s$}

In order to evaluate the proposed system upon implementation, the following indices are used:

Efficacy: Is the data collected and analysed?

Efficiency: How much effort is used for obtaining the data (input) and transforming it and is it all used?

Effectiveness: Does it improve decision making?

\subsection{Conceptual model}

A rich picture of the concept of the proposed FMIS is illustrated in Fig. 5 below. It can be seen that the system comprises a large number of sensors and other systems for data collection on the farm in the course of the crop production cycle. The automatically acquired data complement the monitoring of the operational activities. Furthermore, the structure of the FMIS should enable the interrelation with external systems (e.g. financial, market, administration, etc.).

Fig. 5 shows the processes in the conceptual model as derived from the definition of the system. It is depicted how the operational field data needs to be collected and transformed in an automated way. The filtering of information (external as well as internal field operation data) is initiated by the farm manager according to the operational activity which is to be planed. This relates to issues such as ideas and advice, counselling, information flow from administration and regulations. depicted in the rich pictures. Based on this, an execution plan can be generated and sent to the executer (e.g. the equipment, staff or service provider that is to carry out the operation) and finally, a record of the executed operations will be prepared. In the rich picture, these planning activities are presented as managing field operations, performance monitoring, order manage, manage pay, etc. This reporting subsystem can furthermore be used in documentation of farm practice toward government, buyers or consumers.

Based on this conceptual model for the FMIS derived from SSM analysis, a more formal systems model is presented in Fig. 6 using UML notation.

The model divides the FMIS into four functional components: internal data collection, external information collection, plan generation and report generation. The data collection and processing is an automated monitoring system, whereas the report and plan subsystems are to be initiated by the farm manager. From this component-based model of the required system, the formal specification of the behaviour and interfaces of each component, based on the dependencies illustrated in Fig. 6 (dashed arrows), may be straightforwardly derived and used as the basis for implementations. Table 3 presents some possible implementations of the various components of the proposed FMIS.

The external repository contains information on standards, rules, all types of guidelines for farm activities etc., made available for the FMIS. This should not be understood as a monolithic database, but rather a distributed system such as may be imple- 


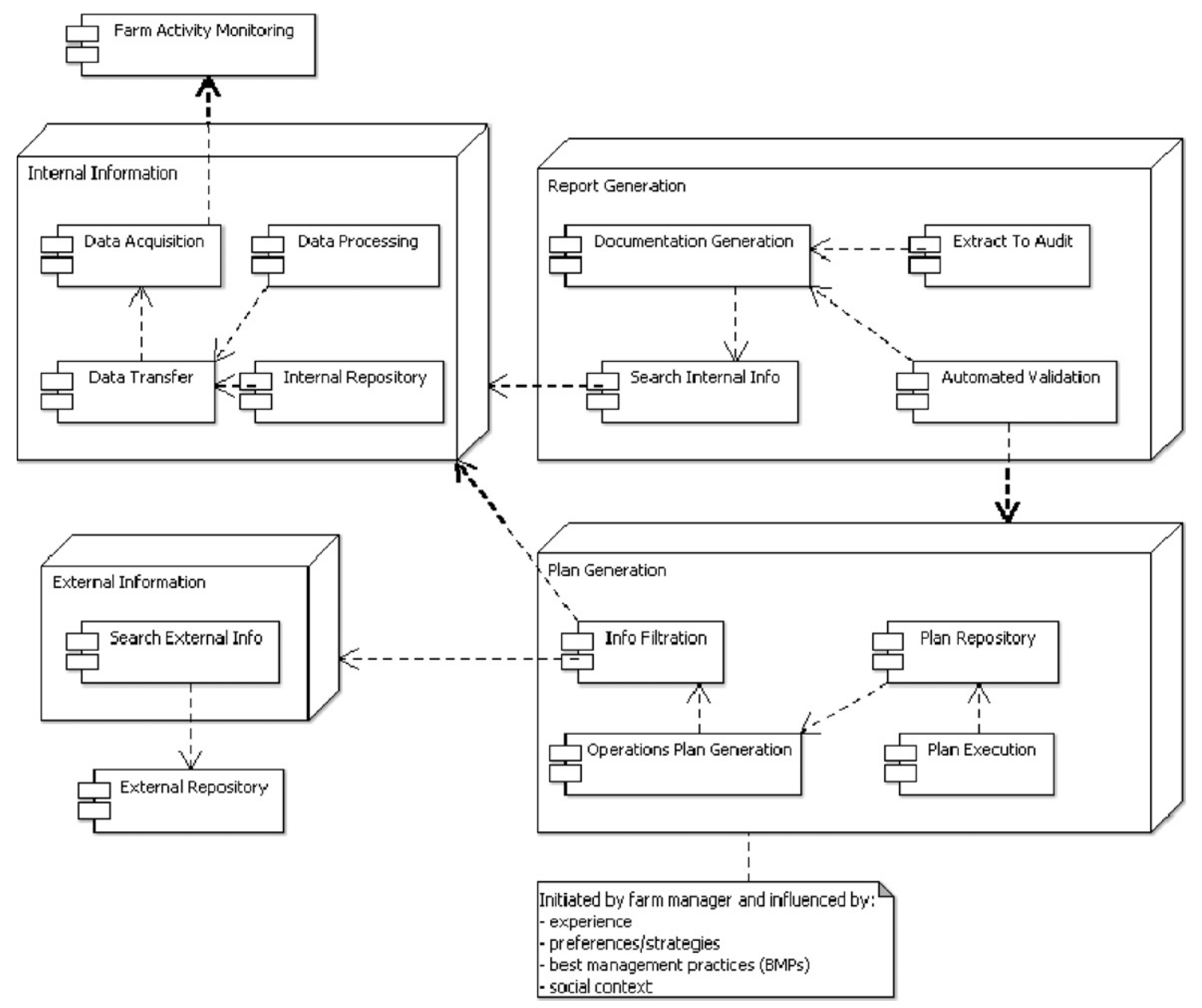

Fig. 6. The concept of the FMIS to be developed.

mented through a form of Service Oriented Architecture (SOA) architecture, providing the necessary open standard interfaces and data transfer formats. The decision making and plan generation performed by the manager are influenced by a number of factors, such as experience, preferences, the availability of best management practises (BMP's), the social context surrounding the manager and chosen management strategy.

\section{Discussion}

The soft systems methodology (SSM) targets organisational business and process modelling and identifies unstructured problems as well as identifying non-obvious problem solutions in a holistic view. Specifically, the approach provides the possibility of more clearly capturing the change that is necessary for a cur-

Table 3

Possible implementations of the component-based model of the FMIS.

\begin{tabular}{|c|c|}
\hline Components & Possible implementations \\
\hline Farm activity monitoring & Sensor readings from process activities (e.g. fuel consumption, yield measurements, RFID, GPS) \\
\hline Data acquisition & apturing of the sensor data and possibly presentation to the user (e.g. tractor terminal, mobile terminal, individual implement displays) \\
\hline Data transfer & $\begin{array}{l}\text { Transfer of the acquired data from the point of creation to some database or processing unit (e.g. GSM, GPRS, WLAN wireless } \\
\text { technologies) }\end{array}$ \\
\hline Data processing & Processing unit aggregating and/or deriving targeted indicators (e.g. central database, web-server, application logic) \\
\hline Internal repository & $\begin{array}{l}\text { Database holding information on the "operations history" of the farm (e.g. local database on the farmer pc or central database, such as } \\
\text { the personalised web-database Danish field database (DAAS, 2009) }\end{array}$ \\
\hline Search internal information & Locate specific information in the internal repository (e.g. specific search application logic) \\
\hline Documentation generation & $\begin{array}{l}\text { Derivation of indicators to evaluate compliance with norms, standards, etc. (e.g. special designed tools for specifying realised application } \\
\text { rates, realised yields, etc.) }\end{array}$ \\
\hline Extract to audit & Extraction of specific information for auditing (e.g. using specialised tools to extract the required and contextualised information) \\
\hline Automated validation & Comparison between documentation and planned activities (e.g. specific tool for automated comparison) \\
\hline Search external information & $\begin{array}{l}\text { Locate specific information in the external distributed repository (e.g. specific search application logic for locating adverse sorts of } \\
\text { guidelines for farming activities) }\end{array}$ \\
\hline Information filtration & $\begin{array}{l}\text { Contextualisation and specification of the needed information for planning purposes (e.g. application software for sorting and } \\
\text { transforming data/information into the right formats, etc.) }\end{array}$ \\
\hline Operations plan generation & $\begin{array}{l}\text { Decision making and plan generation for the farming processes and operations (e.g. specialised planning software modules listing } \\
\text { predicted application rates, machinery input, labour input, etc. - for example AGROffice (2009) }\end{array}$ \\
\hline Plan repository & Repository holding and listing the generated plans at specific times (e.g. a dedicated database) \\
\hline Plan execution & $\begin{array}{l}\text { Actual execution of the planned activities (e.g. invoking different control system - for example downloading task files (task } \\
\text { specification) to the tractor controller (TC) for subsequently execution and control by the implement control unit (ECU)) }\end{array}$ \\
\hline
\end{tabular}


Table 4

Perceived strengths and weaknesses of SSM and UML.

\begin{tabular}{lll}
\hline Modelling technique & Soft systems modelling & Unified modelling language \\
\hline Strengths & Process-oriented methodology & Solution-oriented methodology \\
& Multiple state, both existing and required systems & Hard model, may be directly used in implementations \\
& Explicit identification of current problems and required changes & Easily understood by software engineers and experts \\
& Wide-ranging model & Formal set of semantics and expressions \\
& Easily understood by lay persons & \\
Weaknesses & Soft model, implementation design requires further hard modelling & Single state, either existing system or planned system \\
& Lack of formal semantics, requires interpretation & Hard to understand for lay persons \\
\hline
\end{tabular}

rent system to transform into a proposed system that will fulfil the user requirements of tomorrow. In this way, the SSM becomes a way of interpreting the language of the farmer into a form suitable for the computer scientist. This is an advantage compared with more hard-systems approaches, where, for example, activity diagrams follows a more stringent way of analysing the problem under consideration (Jackson, 2001; Christis, 2005). The SSM capture the issue that information design is not solely about computing but as much about organisational processes and the context in which the designed information system will eventually have to function (Davies, 1989).

Further hard-systems approaches such as Core-Task Analysis have as a prerequisites that the system under consideration is from the start organised in a systematic way (Norros, 2004). The final implementation will require the more hard system requirements analysis but the soft system methodology in this case is seen as preceding the detailed requirements specification in terms of establishing the main components of the system including the system boundaries. Given that farmers report significant problems in using current agricultural information management systems, and particularly in transferring information between systems (e.g. Pederson et al., 2004; Kitchen et al., 2005; Reichardt and Juergens, 2009), and the move to web- and web-service based management systems (e.g. Murakami et al., 2007; Nash et al., 2009b; Nikkilä et al., 2010), a fundamental analysis of current processes and structures, and the problems identified with them, is needed to ensure that the new generation of systems better meet the needs of farmers in terms of functionality, interfaces and parties involved. The use of SSM allows such a fundamental analysis, incorporating the identification of required changes. The unstructured analysis enables the identification of existing constraints, and possible solutions, which may not be apparent using more structured methods (Checkland and Scholes, 1999).

Previous studies analysing information transfers in precision farming, and proposing new models for farm management information systems have tended to use formal, hard-systems analysis techniques. For example, Nash et al. (2007) used UML modelling to identify uses for geospatial web-services, developing a model from use-case analysis through to process modelling and implementation models. Table 4 compares such a hard modelling approach using UML to the SSM approach presented here. In summary, it can be stated that the SSM approach gives more flexibility and a better communication with farmers and other potential end users during the initial analysis phase, and allows the explicit identification of problems and desires for change. However, the informal models resulting from SSM are not in themselves sufficient as the basis for the implementation of new information systems - for this a formal hard-systems modelling approach such as UML is required in order to specify, first in an abstract and subsequently in a detailed technical form, the exact behaviour of different components of the system and their interfaces. The advantage of using SSM is the broader scope of the initial modelling phase, allowing all parties to be involved and to specify both the current and the required systems. The agreed SSM specification of the required system may then be used as the basis for the formal modelling.
It has to be noted that a system may be technical and economic feasible from a hard system perspective but still rejected from other reasons. Soft system issues are often related to personality acceptance and social feasibility. Therefore, issues such as ethics, honesty, good will and moral may have an impact on motivation, de-motivation or acceptance of an innovation/technology solution (Wilson, 1988).

\section{Conclusions}

As part of specifying and designing a new farm information management system (FMIS) for precision farming, a rich picture has been derived capturing the processes and concerns of the farmer in terms of information handling. The focus is on the farm manager and the subsequent everyday management problems with central entities in the proposed system including the farm manager, the fields, the products and production input. Based on the identified boundaries, the system was defined in terms of the derived customers, actors, transformation process, world-view, ownership and environmental constraints.

Based on this initial outline of the system, a conceptual model was derived from the definition of the system. The conceptual model for the FMIS is divided into four sections: internal data collection, external information collection, plan generation and report generation. The data collection and processing is an automated monitoring system, whereas the report and plan subsystems are to be initiated by the farm manager. The external repository contains information on standards, rules, all types of guidelines for farm activities etc., made available for the FMIS.

This research has shown the benefit of using dedicated system analysis methodologies as a preliminary step to the actual design of a novel farm management information system compared with other more rigid and activity oriented system analysis methods. It has been shown that use of SSM allows a fundamental analysis, incorporating the identification of required changes and most importantly, the unstructured analysis enables the identification of existing constraints, and possible solutions, which may not be apparent using more structured methods. The next step in the design process will involve detailing and specifying the information flows inherent in the proposed information system and using formal hard-systems modelling approaches such as UML to produce detailed specifications of each of the identified components.

\section{Acknowledgement}

This project was part of the collaborative research project FutureFarm. The research leading to these results has received funding from the European Community's Seventh Framework Programme (FP7/2007-2013) under grant agreement no. 212117.

\section{References}

AGROffice, 2009. Planning and analysing. PROGIS Software AG. http://www. progis.com. 
Alvarez, J., Nuthall, P., 2006. Adoption of computer based information systems: the case of dairy farmers in Canterbury, NZ, and Florida, Uruguay. Computers and Electronics in Agriculture 50, 48-60.

Atherton, B.C., Morgan, M.T., Shearer, S.A., Stombaugh, T.S., Ward, A.D., 1999. Sitespecific farming: a perspective on information needs, benefits and limitations. Journal of Soil and Water Conservation 54 (2), 455-461.

Attonaty, J.M., Chatelin, M.H., Garcia, F., 1999. Interactive simulation modeling in farm decision-making. Computers and Electronics in Agriculture 22 (2-3), $157-170$.

Bergvall-Kareborn, B., Mirijamdotter, A., Basden, A., 2004. Basic principles of SSM modeling: an examination of CATWOE from a soft perspective. Systemic Practice and Action Research 17 (2), 55-73.

Blackmore, B.S., 2000. Using information technology to improve crop management. In: Weather \& Agro-Environmental Management. AgMet Millennium Conferences, 29th February 2000, pp. 30-38.

Blackmore, B.S., Griepentrog, H.W., Pedersen, M.S., Fountas, S., 2006. Precision farming in Europe. In: Srinivasan, A. (Ed.), Handbook of Precision Farming: Principles and Applications. The Haworth Press, Inc., Binghamton, NY, USA, p. 684.

Carberry, P.S., Hochman, Z., McCown, R.L., Dalgliesh, N.P., Foale, M.A., Poulton, P.L., Hargreaves, J.N.G., Hargreaves, D.M.G., Cawthray, S., Hillcoat, N., Robertson, M.J., 2002. The FARMSCAPE approach to decision support: farmers', advisers', researchers' monitoring, simulation, communication and performance evaluation. Agricultural Systems 74, 141-177.

Checkland, P.B., 1988. Information-systems and systems thinking - time to unite. International Journal of Information Management 8 (4), 239-248.

Checkland, P., Scholes, J., 1999. Soft Systems Methodology in Action. John Wiley \& Sons Ltd., Chichester.

Christis, J., 2005. Theory and practice of soft systems methodology: a performative contradiction? Systems Research and Behavioral Science 22 (1), 11-26.

Danish Agriculture, 2007. Danish Agriculture in Numbers. Land Economic Outlook 2007.

Dalgaard, R., Halberg, N., Kristensen, I.S., Larsen, I., 2006. Modelling representative and coherent Danish farm types based on farm accountancy data for use in environmental assessments. Agriculture, Ecosystems and Environment 117, 223-237.

DAAS, 2009. Danish Field Database. The Danish Agricultural Advisory Service.

Davies, L.J., 1989. Designing from ill-defined problems. International Journal of Information Management 9.3, 199-208, 1989.

Folinas, D., 2007. A conceptual framework for business intelligence based on activities monitoring systems. International Journal of Intelligent Enterprise 1 (1), 65, 2007.

Fountas, S., Ess, D., Sørensen, C.G., Hawkins, S., Blumhoff, G., Blackmore, S., Lowenberg-DeBoer, J., 2005. Farmer experience with precision agriculture in Denmark and the US eastern corn belt. Precision Agriculture 6, 121-141.

Fountas, S., Wulfsohn, D., Blackmore, B.S., Jacobsen, H.L., Pedersen, S.M., 2006. A model of decision-making and information flows for information-intensive agriculture. Agricultural Systems 87 (2), 192-210.

Fountas, S., Kyhn, M., Lipczak Jakobsen, H., Blackmore, S., Griepentrog, H.W., 2009. Systems analysis and information management of a university research farm. Precision Agriculture 10 (3), 247-261.

Gunasekaran, A., Ngai, E.W.T., 2004. Information systems in supply chain integration and management. European Journal of Operational Research 159.2, 269-295, 2004.

Halberg, N., 2001. Indicators of resource use and environmental impact for use in a decision aid for Danish livestock farmers. Agriculture, Ecosystems and Environment 76, 17-30.

Jackson, M.C., 2001. Critical systems thinking and practice. European Journal of Operational Research 128 (2), 233-244, 2001.

Jensen, L.A., Sørensen, C.G., Jørgensen, R.N., 2007. Real-time internet-based traceability unit for mobile payload vehicles. In: Proceedings of the XXXII CIOSTA-CIGR Section V Conference "Advances in Labour and Machinery Management for a Profitable Agriculture and Forestry", pp. 368-374.

Jensen, A.L., Boll, P.S., Thysen, I., Pathak, B.K., 2001. Pl@nteInfo ${ }^{\circledR}-$ a web-based system for personalised decision support in crop management. Computers and Electronics in Agriculture 25 (3), 271-293.

Kasimin, H., Yusoff, M., 1996. The use of a soft systems approach in developing information systems for development planning: an exploration in regional planning. Computers, Environment and Urban Systems 20, 165-180.

Kitchen, N.R., Snyder, C.J., Franzen, D.W., Wiebold, W.J., 2005. Educational needs of precision agriculture. Precision Agriculture 3 (4), 341-351.

Kuhlman, F., Brodersen, C., 2001. Information technology and farm management: developments and perspectives. Computers and Electronics in Agriculture 30, $71-83$.
Lewis, T., 1998. Evolution of farm management information systems. Computers and Electronics in Agriculture 19 (3), 233-248

Macadam, R., Britton, I., Russell, D., Potts, W., Baillie, B., Shaw, A., 1990. The use of soft systems methodology to improve the adoption by Australian cotton growers of the siratac computer-based crop management system. Agricultural Systems 34 , $1-14$.

McCarthy, J.J., 1990. The challenge of CIM in the process industries. ISA Transactions $29(1), 53-56$.

McCown, R.L., 2002. Changing systems for supporting farmers_decisions: problems, paradigms and prospects. Agricultural Systems 74, 179-220.

Murakami, E., Saraiva, A.M., Ribeiro Jr., L.C.M., Cugnasca, C.E., Hirakawa, A.R., Correa, P.L.P., 2007. An infrastructure for the development of distributed service-oriented information systems for precision agriculture. Computers and Electronics in Agriculture 58 (1), 37-48.

Nash, E., Bill, R., Bobert, J., 2007. Anwendungsfallanalyse für den Einsatz von GDITechnologien in Precision Farming ((Use-case analysis for the application of SDI-technologies in precision farming)). GIS-Zeitschrift für Geoinformatik 11, 14-21.

Nash, E., Dreger, F., Schwarz, J., Bill, R., Werner, A., 2009a. Development of a model of data-flows for precision agriculture based on a collaborative research project. Computers and Electronics in Agriculture 66 (1), 25-37.

Nash, E., Korduan, P., Bill, R., 2009b. Applications of open geospatial web services in precision agriculture: a review. Precision Agriculture 10 (6), 546-560.

Nagalingam, V. Ser, Grier, C.I. Lin, 2008. CIM - still the solution for manufacturing industry.". Robotics and Computer-Integrated Manufacturing 24 (3), 332-344.

Nidumolu, U.B., De Bie, C.A.J.M., van Keulen, H., Skidmore, A.K., Harmsen, K., 2006. Review of a land use planning programme through the soft systems methodology. Land Use Policy 23 (2), 187-203.

Nikkilä, R., Seilonen, I., Koskinenet, K., 2010. Software architecture for farm management information systems in precision agriculture. Computers and Electronics in Agriculture 70 (2), 328-336.

Norros, L., 2004. Acting under Uncertainty. The Core-task Analysis in Ecological Study of Work. Espoo, VTT, Finland.

O’Brien, J., 1999. Management Information Systems - Managing Information Technology in the Internetworked Enterprise. Irwin McGraw-Hill, Boston.

Ohlmer, B., Olson, K., Brehmer, B., 1998. Understanding farmers' decision making processes and improving managerial assistance. Agricultural Economics 18, 273-290.

Pedersen, S.M., Fountas, S., Blackmore, B.S., Gylling, M., Pedersen, J.L., 2004. Adoption and perspective of precision farming in Denmark. Acta Agriculturae Scandinavica Section B, Soil and Plant Science 54 (1), 2-6.

Reid, J.I., Gray, D.I., Kelly, T.C., Kemp, E.A., 2000. An application of SSM in the onfarm labour situation in the New Zealand dairy industry. Systems Research and Behavioral Science 16, 250-341.

Reichardt, M., Juergens, C., 2009. Adoption and future perspective of precision farming in Germany: results of several surveys among different agricultural target groups. Precision Agriculture 10 (1), 73-94.

Riezebos, J., Klingenberg, W., Hicks, C., 2009. Lean production and information technology: connection or contradiction? Computers in Industry 60 (4), 237-247.

Sigrimis, N., Hashimoto, Y., Munack, A., De Baerdemaeker, J., 1999. Prospects in agricultural engineering in the information age: technological developments for the producer and the consumer. CIGR-Ejour I, 1-20.

Speckman, H., Munach, A., 2001. Communication technology is the backbone of precision agriculture. Agricultural Engineering International: The CIGR Journal of Scientific Research and Development 3.

Staker, R.J., 1999. An Application of Checkland's Soft Systems Methodology to the Development of a Military Information Operations Capability for the Australian Defence Force. Defence Science and Technology Organisation Canberra, Australia, DSTO-TN-0183, p. 17.

Sørensen, C.G. Suomi, P. Kaivosoja, J., Pesonen, L, 2007. Functional Environment of a Mobile Work Unit. InfoXT - User-centric Mobile Information Management in Automated Plant Production. MTT Agrifood Research Finland.

Sørensen, C., Bildsøe, P., Fountas, S., Pesonen, L., Pedersen, S., Basso, B., Nash, E., 2009. System Analysis and Definition of System Boundaries. FutureFarm, Report No. 3.1, www.futurefarm.eu.

Walker, D.H., Cowell, S.G., Johnson, A.K.L., 2001. Integrating research results into decision making about natural resource management at a catchment scale. Agricultural Systems 69, 85-98.

Wilson, B., 2001. Soft Systems Methodology. John Wiley \& Sons Ltd.

Wilson, J., 1988. Changing Agriculture, An Introduction to Systems Thinking. Kangaroo Press. 